\title{
The combinations of polymorphisms in vitamin $D$ receptor, osteoprotegerin and tumour necrosis factor superfamily member 11 genes are associated with bone mineral density
}

\author{
Simona Mencej-Bedrač, Janez Preželj ${ }^{1}$, Tomaž Kocjan ${ }^{1}$, Karmen Teskač ${ }^{2}$, Barbara Ostanek, \\ Mojca Šmelcer and Janja Marc
}

Department of Clinical Biochemistry, Faculty of Pharmacy, University of Ljubljana, Askerceva cesta 7, SI-1000 Ljubljana, Slovenia

${ }^{1}$ Department of Endocrinology, Diabetes and Metabolic Diseases, University Medical Centre, Zaloska cesta 2, SI-1000 Ljubljana, Slovenia

${ }^{2}$ Department of Pharmaceutical Technology, Faculty of Pharmacy, University of Ljubljana, Askerceva cesta 7, SI-1000 Ljubljana, Slovenia

(Correspondence should be addressed to J Marc; Email: janja.marc@ ffa.uni-lj.si)

\begin{abstract}
1 $\alpha, 25$-dihydroxyvitamin $D_{3}$ upregulates tumour necrosis factor superfamily member 11 (TNFSF11) that codes for the receptor activator of nuclear factor $\kappa B$ ligand (RANKL), and downregulates osteoprotegerin $(O P G)$ expression. We have analyzed the individual effects of polymorphisms in the vitamin D receptor gene (VDR), OPG and TNFSF11, and searched for interactions between them. Six hundred and forty one subjects were evaluated: 239 osteoporotic and 228 non-osteoporotic post-menopausal, 57 pre-menopausal women and 117 elderly men. The subjects were genotyped for Bsml, Fokl and Cdx2 in VDR, K3N in OPG and $-290 \mathrm{C}>\mathrm{T},-643 \mathrm{C}>\mathrm{T}$ and $-693 \mathrm{G}>\mathrm{C}$ in TNFSF11 gene. Bone mineral density (BMD) and biochemical markers were measured. In the osteoporotic women, femoral neck BMD (BMD-fn) showed associations with $B s m l(V D R)$ and $\mathrm{Cdx} 2(V D R)(P=0.015$ and 0.047 respectively), and lumbar spine BMD (BMDIs) with $\mathrm{K} 3 \mathrm{~N}(O P G)$ and $-290 \mathrm{C}>\mathrm{T}(\mathrm{TNFSF} 11)(P=0.021$ and 0.017$)$. No association with BMD was found in the nonosteoporotic women. In the pre-menopausal women, the $\mathrm{Cdx2}(V D R)$ polymorphism was associated with BMD-fn and total hip BMD $(P=0.011$ and 0.011). In elderly men, Fokl(VDR) was associated with BMD-fn and BMD-ls $(P=0.040$ and $0.036)$. Interestingly, the $-290 \mathrm{C}>\mathrm{T}(\mathrm{TNFSF11}) \mathrm{K} 3 \mathrm{~N}(O P G)$ combination was associated with BMD-th $(P=0.041)$ in the osteoporotic women. In the non-osteoporotic women, the combination $\mathrm{K} 3 \mathrm{~N}(O P G)-\mathrm{Cdx} 2(V D R)$ was associated with BMD-Is, BMD-th and BMD-fn $(P=0.032,0.049$ and 0.022), and the combination -290C $>\mathrm{T}(T N F S F 11)$ K3N $(O P G)$ with BMD-fn $(P=0.029)$. For the first time, the presence of gene-gene interactions between VDR, OPG and TNFSF11 genes was studied. Our results strongly suggest further confirmation of their combined influence on larger cohorts.
\end{abstract}

Journal of Molecular Endocrinology (2009) 42, 239-247

\section{Introduction}

Osteoporosis is a common multifactorial disease characterized by reduced bone mass and strength, changes in the microarchitecture of bone tissue and an increased risk of fracture. Fracture affects up to $30 \%$ of women and $12 \%$ of men at some point. Bone mineral density (BMD) is accepted as the primary clinical predictor of fracture risk and is genetically determined. Twin and family studies show heritability of $50-85 \%$ for peak bone mass (Ralston \& de Crombrugghe 2006).

$1 \alpha, 25$-dihydroxyvitamin $\mathrm{D}_{3}\left(1 \alpha, 25(\mathrm{OH})_{2} \mathrm{D}_{3}\right)$ plays a central role in skeletal metabolism by binding to its nuclear steroid receptor, vitamin $\mathrm{D}$ receptor (VDR). $1 \alpha, 25(\mathrm{OH})_{2} \mathrm{D}_{3}$ can stimulate bone formation and resorption, regulating bone turnover by acting on both osteoblastic and osteoclastic lineage cells (Baldock et al. 2006). Recent data show that $1 \alpha, 25(\mathrm{OH})_{2} \mathrm{D}_{3}$ is also involved in the regulation of local factors such as osteoprotegerin (OPG)/receptor activator of nuclear factor $\kappa \mathrm{B}$ ligand (RANKL)/RANK system. In the OPG/ RANKL/RANK system, OPG acts as a decoy receptor for RANKL (Yasuda et al. 1999) and inhibits osteoclast differentiation, survival and function in vitro and bone resorption in vivo (Kondo et al. 2004) by preventing the interaction of RANKL with its receptor RANK. $1 \alpha, 25(\mathrm{OH})_{2} \mathrm{D}_{3}$ affects OPG and RANKL in a reciprocal manner, promoting osteoclastogenesis by upregulating the expression of RANKL and downregulating the expression of OPG (Kondo et al. 2004). In mice, $1 \propto, 25(\mathrm{OH})_{2} \mathrm{D}_{3}$ transiently suppressed $O P G$ gene expression by suppressing $O P G$ promoter activity through the AP-1 binding site and by accelerating degradation of $O P G$ mRNA (Kondo et al. 2004). In the tumour necrosis factor superfamily member 11 (TNFSF11) gene that codes for RANKL protein, vitamin D response elements (VDREs) have been identified in the mouse promoter region (Kitazawa et al. 1999). 
In mice and in humans, several distal regulatory regions in TNFSF11 gene promoter have been found to mediate the activity of $1 \alpha, 25(\mathrm{OH})_{2} \mathrm{D}_{3}$ through VDR and contain functional VDREs (Kim et al. 2006, Nerenz et al. 2008).

As osteoporosis is a disease with a strong genetic component, much effort is focused on the identification of single nucleotide polymorphisms (SNPs) associated with the osteoporotic phenotype (Ralston $\&$ de Crombrugghe 2006). The outbreak of genetic association studies on osteoporosis started with the reported association between VDR alleles and BMD (Morrison et al. 1994). Numerous association studies have been performed on the VDR gene and BMD showing conflicting results (Thakkinstian et al. 2004, Fang et al. 2005, Zintzaras et al. 2006). In a prospective multicentre large-scale association study involving 26242 participants, only the Cdx2 polymorphism in the VDR gene was found to be associated with the risk of vertebral fractures (Uitterlinden et al. 2006). In the $O P G$ gene, several association studies have consistently shown an association of the K3N polymorphism with the osteoporotic phenotype (Langdahl et al. 2002, Arko et al. 2005, Choi et al. 2005, Zhao et al. 2005, Kim et al. 2007, García-Unzueta et al. 2008). However, some studies revealed a non-significant association of K3N with the osteoporotic phenotype (Wynne et al. 2002, Ueland et al. 2007). Two recently published genomewide association analyses have identified the $O P G$ gene as playing a key role in the biological characteristics of bone (Richards et al. 2008, Styrkarsdottir et al. 2008). Association with the osteoporotic phenotype has not been widely studied in the TNFSF11 gene (Hsu et al. 2006, Kim et al. 2007, Mencej et al. 2008). However, a functional role has been established for some SNPs in the TNFSF11 promoter (Mencej et al. 2008).

Based on the new data on the crosstalk between RANKL/RANK/OPG and vitamin D pathways, we have examined the possibility of their combined influence on the risk of osteoporosis. The VDR, OPG and TNFSF11 genes have been studied as candidate genes for the regulation of susceptibility to osteoporosis. As the combined influence of the risk alleles of the VDR, $O P G$ and TNFSF11 gene SNPs on BMD has not been elucidated, our aim was to examine the potential combined influence of risk genotypes on BMD at different sites in post-menopausal women.

\section{Materials and methods}

\section{Subjects}

We evaluated 641 subjects, who had been referred to the outpatient departments of the University Medical Centre, Ljubljana, the General and Teaching Hospital, Celje or the Teaching Hospital, Maribor, Slovenia for
BMD measurement. On the basis of gender and menopausal status, the subjects were divided into four subgroups: 239 osteoporotic and 228 non-osteoporotic post-menopausal women, 57 pre-menopausal women and 117 elderly men. Each patient was examined clinically and routine biochemical tests were performed to exclude systemic and metabolic bone diseases other than primary osteoporosis. None had previously taken any drug known to influence bone metabolism. Osteoporosis was defined according to the World Health Organization criteria (WHO 1994). The study was approved by the Ethical Committee of the Republic of Slovenia and written informed consent was obtained from each subject participating in the study. The study was conducted in compliance with national legislation and the Declaration of Helsinki.

\section{Genotyping}

Genomic DNA was isolated from peripheral blood leukocytes using standard methodology. The TaqMan allelic discrimination method, using the TaqMan SNP genotyping assays (Applied Biosystems, Foster City, CA, USA) with slight modifications, was used for genotyping of the following SNPs: K3N (rs2073618) in the OPG gene, and $-290 \mathrm{C}>\mathrm{T}(\mathrm{rs} 9525641)$ in the TNFSF11 gene. Reactions were performed on an ABI Prism 7000 sequence detection system (Applied Biosystems).

PCR primers were designed for SNPs $-643 \mathrm{C}>\mathrm{T}$ (rs9533156) and $-693 \mathrm{G}>\mathrm{C} \quad(\mathrm{rs} 9533155)$ in the TNFSF11 gene, and BsmI (rs1544410), FokI (rs2228570) and Cdx2 (rs11568820) in the VDR gene, based on the gene sequences available in GenBank (accession numbers AF544022 for TNFSF11 and AY342401 for $V D R)$. The subjects were genotyped for the presence of $-643 \mathrm{C}>\mathrm{T}($ TNFSF11) and $-693 \mathrm{G}>\mathrm{C}($ TNFSF11) as described previously (Mencej et al. 2006).

For genotyping Bsm $(V D R)$ and FokI $(V D R)$ two pairs of primers were used for duplex PCR: the first pair of sense $5^{\prime}$-GGCAACCTGAAGGGAGACGTA- $3^{\prime}$ and antisense $5^{\prime}$-CTCTTTGGACCTCATCACCGAC-3 ${ }^{\prime}$ primers, and the second pair of sense $5^{\prime}$-AGCTGGCCCTGGCACTGACTCTGCTCT- $3^{\prime}$ and antisense $5^{\prime}$-ATGGAAACACCTTGCTTCTTCTCCCTC-3' $3^{\prime}$ primers. Cycling conditions consisted of an initial $12 \mathrm{~min}$ at $95^{\circ} \mathrm{C}$ followed by 40 cycles of $30 \mathrm{~s}$ at $94^{\circ} \mathrm{C}, 45 \mathrm{~s}$ at $56^{\circ} \mathrm{C}$, $30 \mathrm{~s}$ at $72{ }^{\circ} \mathrm{C}$, and finally, $8 \mathrm{~min}$ at $72^{\circ} \mathrm{C}$. For genotyping Cdx2(VDR) the following PCR primers were used: sense $5^{\prime}$-ACTGCAGCCTTGACCTCCTA- $3^{\prime}$ and antisense 5'-AAAGCAAACCAAGGGGTCTT-3'. Cycling conditions consisted of an initial $10 \mathrm{~min}$ at $95^{\circ} \mathrm{C}$ followed by 36 cycles of $45 \mathrm{~s}$ at $95^{\circ} \mathrm{C}, 20 \mathrm{~s}$ at $58^{\circ} \mathrm{C}$, $45 \mathrm{~s}$ at $72^{\circ} \mathrm{C}$ and finally, $7 \mathrm{~min}$ at $72^{\circ} \mathrm{C}$. The PCR mixture $(20 \mu \mathrm{l})$ contained genomic DNA $(100 \mathrm{ng}), 1 \times$ PCR buffer, $2 \cdot 0 \mathrm{mM} \mathrm{MgCl}_{2}, 0 \cdot 3 \mathrm{mM}$ each of the four deoxyribonucleotides, $0 \cdot 125-0 \cdot 375 \mu \mathrm{M}$ each of 
oligonucleotide primers and $1.0 \mathrm{U}$ AmpliTaq Gold polymerase (Applied Biosystems, Roche Molecular Systems, Inc). For analysis of the VDR gene SNPs, the following restriction enzymes were used as outlined by the manufacturer (New England Biolabs, Beverly, MA, USA): BsaI for BsaI, FokI for FokI and HypCHIII for Cdx2 polymorphism.

\section{BMD measurement}

BMD measurements at the lumbar (L1-L4) spine (BMD-ls), total hip (BMD-th) and femoral neck (BMD-fn) were performed by dual-energy X-ray absorptiometry (QDR-4500, Hologic Inc., Waltham, MA, USA) in Ljubljana, Celje and Maribor. Crosscalibration study of all three facilities was performed by having one technologist do ten phantom scans with repositioning, as recommended by the ISCD for the systems with the same technology (manufacturer and model; Shepherd et al. 2006). We found a negligible difference in mean BMD between facilities, so a correction factor was not considered necessary.

\section{Biochemical markers of bone turnover}

Biochemical markers of bone turnover were measured in a subset of 152 post-menopausal women. Blood samples were collected between 0800 and $1000 \mathrm{~h}$ after an overnight fast. The plasma and serum samples were analysed in a routine laboratory using standard procedures as outlined by the manufacturers. Osteocalcin (OC) in heparinized plasma was measured by a solid-phase, two-site chemiluminescent enzymelabelled immunometric assay (Immulite Osteocalcin, Diagnostic Product Corporation, Los Angeles, CA, USA). Serum bone alkaline phosphatase (BALP) was measured by RIA (Tandem-R Ostase, Beckman Coulter, Fullerton, CA, USA). Serum C-terminal crosslinking telopeptides of type I collagen (CTX) were measured by enzyme immunoassay (Serum CrossLaps ELISA, Nordic Bioscience Diagnostics A/S, Herlev, Denmark). Serumfree soluble RANKL (sRANKL) was measured by an enzyme immunoassay (sRANKL ELISA, Biomedica, Vienna, Austria) and OPG by enzyme immunoassay (Human Osteoprotegerin ELISA, BioVendor Laboratory Medicine Inc., Modrice, Czech Republic).

\section{Statistical analysis}

Hardy-Weinberg equilibrium was tested for each SNP and group of participants using the $\chi^{2}$ test. Frequency distributions of genotypes in the osteoporotic and nonosteoporotic post-menopausal women were compared for each studied SNP using the $\chi^{2}$ test. The standardized measures of linkage disequilibrium (LD), denoted as $D^{\prime}$ and $r^{2}$, were assessed using the EMLD software that calculates pair-wise LD based on SNP genotype data from unrelated individuals (https://cge.mdanderson. org/ qhuang/software/pub.htm). For two independent loci, the difference $(D)$ is that between the actual and expected gametic frequencies and is usually expressed as a standardized difference $\left(D^{\prime}\right)$. $D$ measures the statistical association of alleles in forming gametes and is related to the Pearson correlation coefficient $(r)$. $D^{\prime}$ is used to assess the probability of historical recombination, whereas $r^{2}$ is the most relevant measure in the association studies (Mueller 2004). KolmogorovSmirnov normality test was conducted before association analysis and data transformation was performed where appropriate. The differences in age, weight, height, body mass index (BMI), age at menopause and years since menopause between genotype subgroups were tested using ANOVA. No differences were observed. In the present study, each subgroup of subjects was analyzed separately. Therefore, no comparison of basic characteristics was made between groups of subjects, as no influence on the results of the association analysis would be expected. Differences in $\mathrm{BMD}$ and biochemical markers between the genotype subgroups were tested using ANOVA or non-parametric Kruskal-Wallis test. To analyze the interaction between different pairs of SNPs, the differences in BMD were tested with two-way ANOVA. Statistical analyses were carried out using SPSS version 16.0 (SPSS Inc., Chicago, IL, USA) and $p$ values less than 0.05 were considered statistically significant.

\section{Results}

In the present study, the impact of the individual SNPs on the VDR, OPG and TNFSF11 genes was established to identify the risk polymorphisms for assessing their combined influence on the BMD. The genotype frequencies of all studied SNPs were determined by screening DNA samples from 641 subjects. The genotype frequencies of all the subgroups are summarized in Table 1. The genotype frequency distributions of all seven polymorphic SNPs were in Hardy-Weinberg equilibrium. Comparison of genotype frequencies between osteoporotic and non-osteoporotic post-menopausal women revealed statistically significant differences only in FokI $(V D R)$ and Cdx2(VDR) $(P=0 \cdot 041$ and $0 \cdot 037)$.

In the TNFSF11 gene promoter SNPs, evidence of strong $\mathrm{LD}$ was shown within each of the three possible pairs: $-290 \mathrm{C}>\mathrm{T}$ and $-643 \mathrm{C}>\mathrm{T}, D^{\prime}=0 \cdot 96, r^{2}=0 \cdot 87$; $-290 \mathrm{C}>\mathrm{T}$ and $-693 \mathrm{G}>\mathrm{C}, \quad D^{\prime}=0.93, \quad r^{2}=0 \cdot 84$; $-643 \mathrm{C}>\mathrm{T}$ and $-693 \mathrm{G}>\mathrm{C}, D^{\prime}=0 \cdot 92, r^{2}=0 \cdot 78$. In the VDR gene SNPs, no evidence of LD was obtained 
Table 1 Genotype frequency distributions in osteoporotic and non-osteoporotic post-menopausal women, pre-menopausal women and in elderly men

\begin{tabular}{|c|c|c|c|c|}
\hline & $\begin{array}{l}\text { Osteoporotic } \\
\text { post-menopausal women }\end{array}$ & $\begin{array}{l}\text { Non-osteoporotic } \\
\text { post-menopausal women }\end{array}$ & Pre-menopausal women & Men \\
\hline$N$ & 239 & 228 & 57 & 117 \\
\hline GG & $103(42 \cdot 9)$ & $88(38 \cdot 6)$ & $21(36 \cdot 8)$ & $32(27 \cdot 4)$ \\
\hline$A G$ & $110(45 \cdot 8)$ & $100(43.9)$ & $27(47 \cdot 4)$ & $58(49 \cdot 6)$ \\
\hline AA & $27(11 \cdot 2)$ & $40(17 \cdot 5)$ & $9(15 \cdot 8)$ & $27(23 \cdot 1)$ \\
\hline CT & $108(45 \cdot 0)$ & $97(42 \cdot 5)$ & $25(43.9)$ & $59(50 \cdot 4)$ \\
\hline TT & $44(18 \cdot 3)$ & $26(11 \cdot 4)$ & $12(21 \cdot 1)$ & $16(13 \cdot 7)$ \\
\hline \multicolumn{5}{|c|}{$C d x 2(r s 11568820)$} \\
\hline GG & $155(64 \cdot 6)$ & $172(75 \cdot 4)$ & $43(75 \cdot 4)$ & $80(68.4)$ \\
\hline GA & $75(31 \cdot 2)$ & $48(21 \cdot 1)$ & $11(19 \cdot 3)$ & $32(27 \cdot 4)$ \\
\hline $\mathrm{AA}$ & $9(3 \cdot 8)$ & $8(3.5)$ & $3(5 \cdot 3)$ & $5(4 \cdot 3)$ \\
\hline \multicolumn{5}{|c|}{ K3N (rs2073618) } \\
\hline $\mathrm{CC}$ & $48(20 \cdot 0)$ & $55(24 \cdot 1)$ & $18(31 \cdot 6)$ & $21(17 \cdot 9)$ \\
\hline $\mathrm{CT}$ & $118(49 \cdot 2)$ & $106(46 \cdot 5)$ & $28(49 \cdot 1)$ & $51(43.6)$ \\
\hline $\mathrm{TT}$ & $74(30 \cdot 8)$ & $67(29 \cdot 4)$ & $11(19 \cdot 3)$ & $45(38.5)$ \\
\hline \multicolumn{5}{|c|}{$-643 C>T(r s 9533156)$} \\
\hline $\mathrm{CC}$ & $42(17 \cdot 5)$ & $54(23 \cdot 7)$ & $16(28 \cdot 1)$ & $22(18 \cdot 8)$ \\
\hline CT & $126(52 \cdot 5)$ & $106(46 \cdot 5)$ & $30(52 \cdot 6)$ & $51(43.6)$ \\
\hline TT & $72(30 \cdot 0)$ & $68(29 \cdot 8)$ & $11(19 \cdot 3)$ & $44(37 \cdot 6)$ \\
\hline \multicolumn{5}{|c|}{$-693 G>C(r s 9533155)$} \\
\hline GG & $42(17 \cdot 5)$ & $53(23 \cdot 2)$ & $15(26 \cdot 3)$ & $20(17 \cdot 1)$ \\
\hline GC & $126(52 \cdot 5)$ & $110(48 \cdot 2)$ & $34(59 \cdot 6)$ & $51(43 \cdot 6)$ \\
\hline $\mathrm{CC}$ & $72(30 \cdot 0)$ & $65(28 \cdot 5)$ & $8(14 \cdot 0)$ & $46(39 \cdot 3)$ \\
\hline
\end{tabular}

OPG, osteoprotegerin; TNFSF11, tumour necrosis factor superfamily, member 11 and VDR, vitamin D receptor. Values are numbers (\%).

between any of the three possible pairs: BsmI and FokI, $D^{\prime}=0 \cdot 04, r^{2}=0 \cdot 002 ; B s m \mathrm{I}$ and Cdx2, $D^{\prime}=0 \cdot 16, r^{2}=$ 0.008; FokI and Cdx2, $D^{\prime}=0 \cdot 18, r^{2}=0 \cdot 004$.

Subject characteristics are presented in Table 2. For each genotype, the differences in age, weight, height and BMI between genotype subgroups were compared in the subgroups of non-osteoporotic and osteoporotic post-menopausal women, pre-menopausal women and in men. In the non-osteoporotic and osteoporotic post-menopausal women, the difference in age at menopause and years since menopause were also tested. No statistically significant differences were identified.

In the osteoporotic post-menopausal women, statistical analysis showed an association with BMD for the following SNPs: $B s m \mathrm{I}(V D R)$ and $\operatorname{Cdx} 2(V D R)$, $\mathrm{K} 3 \mathrm{~N}(O P G)$ and $-290 \mathrm{C}>\mathrm{T}($ TNFSF11) (Table 3). In the non-osteoporotic women, no association with BMD was found in any of the SNPs under study. In the premenopausal women, association of BMD-fn and BMDth with the Cdx2(VDR) polymorphism was identified $(P=0.011$ and $0 \cdot 011)$. In elderly men, association of BMD-fn and BMD-ls with the FokI (VDR) polymorphism was identified $(P=0 \cdot 040$ and $0 \cdot 036)$.
The concentrations of OC, BALP, CTX, RANKL and OPG were measured in 152 post-menopausal women. In the non-osteoporotic women, association was found between -693G $>\mathrm{C}($ TNFSF11) and OC and BALP concentrations $(P=0 \cdot 048$ and $0 \cdot 005)$. In the other studied SNPs, no significant association with biochemical markers of bone turnover was identified in any of the groups.

Multiple SNPs were associated with BMD only in the osteoporotic and non-osteoporotic post-menopausal women. No significant differences were found between the frequencies of combined genotypes in the osteoporotic and non-osteoporotic post-menopausal women. The results of the combined influences of different pairs of SNPs are summarized in Table 4.

\section{Discussion}

In our study, a total of 7 SNPs were studied in the VDR, OPG and TNFSF11 gene. In the osteoporotic post-menopausal women, BMD-fn was associated with $B s m \mathrm{I}(V D R)$ and $\mathrm{Cdx} 2(V D R)$ and BMD-ls with $\mathrm{K} 3 \mathrm{~N}(O P G)$ and $-290 \mathrm{C}>\mathrm{T}($ TNFSF11). In the 
Table 2 Characteristics of the post-menopausal women, non-osteoporotic and osteoporotic, pre-menopausal women and men

\begin{tabular}{|c|c|c|c|c|}
\hline & $\begin{array}{l}\text { Osteoporotic } \\
\text { post-menopausal } \\
\text { women }\end{array}$ & $\begin{array}{l}\text { Non-osteoporotic } \\
\text { post-menopausal } \\
\text { women }\end{array}$ & $\begin{array}{l}\text { Pre-menopausal } \\
\text { women }\end{array}$ & Men \\
\hline Age (years) & $64 \cdot 5 \pm 8 \cdot 2$ & $61 \cdot 5 \pm 8 \cdot 3$ & $45 \cdot 4 \pm 4 \cdot 6$ & $67 \cdot 6 \pm 6 \cdot 1$ \\
\hline Weight $(\mathrm{kg})$ & $66 \cdot 0 \pm 10 \cdot 0$ & $73 \cdot 6 \pm 13 \cdot 0$ & $65 \cdot 4 \pm 11 \cdot 8$ & $81 \cdot 7 \pm 12 \cdot 8$ \\
\hline Height (m) & $158 \cdot 6 \pm 6 \cdot 2$ & $161 \cdot 2 \pm 5 \cdot 8$ & $163 \cdot 8 \pm 6 \cdot 2$ & $171 \cdot 1 \pm 5 \cdot 9$ \\
\hline Years since menopause (years) & $15 \cdot 3 \pm 9 \cdot 4$ & $10 \cdot 4 \pm 8 \cdot 6$ & / & / \\
\hline Femoral neck BMD $\left(\mathrm{g} / \mathrm{cm}^{2}\right)$ & $0.625 \pm 0.083$ & $0.765 \pm 0.121$ & $0.782 \pm 0.077$ & $0.813 \pm 0.159$ \\
\hline Femoral neck $T$-score & $-2 \cdot 3 \pm 0.8$ & $-1 \cdot 0 \pm 1 \cdot 0$ & $-0.7 \pm 0.7$ & $-1 \cdot 2 \pm 1 \cdot 2$ \\
\hline Total hip BMD $\left(\mathrm{g} / \mathrm{cm}^{2}\right)$ & $0.755 \pm 0.099$ & $0.916 \pm 0.137$ & $0.921 \pm 0.092$ & $1 \cdot 024 \pm 0.165$ \\
\hline Total hip T-score & $-1 \cdot 5 \pm 0.8$ & $-0 \cdot 3 \pm 1 \cdot 1$ & $-0.3 \pm 0.7$ & $-0 \cdot 2 \pm 1 \cdot 1$ \\
\hline Lumbar spine BMD $\left(\mathrm{g} / \mathrm{cm}^{2}\right)$ & $0.742 \pm 0.088$ & $0.974 \pm 0.139$ & $1 \cdot 001 \pm 0 \cdot 115$ & $1.057 \pm 0.176$ \\
\hline sRANKL (pmol/l) & $0.3 \pm 0.6$ & $0.4 \pm 0.5$ & / & / \\
\hline OPG (pmol/l) & $64 \cdot 3 \pm 188 \cdot 7$ & $145 \cdot 7 \pm 170 \cdot 6$ & I & l \\
\hline
\end{tabular}

BMI, body mass index; BMD, bone mineral density; CTX, C-terminal crosslinking telopeptides of type I collagen (CTX); sRANKL, soluble receptor activator of nuclear factor $\mathrm{KB}$ ligand and $\mathrm{OPG}$, osteoprotegerin.

non-osteoporotic post-menopausal women, only OC and BALP concentrations were associated with -693G $>\mathrm{C}($ TNFSF 1 1), but no association with BMD was found in any of the studied SNPs. In the premenopausal women, the $\mathrm{Cdx} 2(V D R)$ polymorphism was associated with BMD-fn and BMD-th. In elderly men, FokI $(V D R)$ was associated with BMD-fn and BMD-ls. The combination of $-290 \mathrm{C}>\mathrm{T}($ TNFSF11) and $\mathrm{K} 3 \mathrm{~N}(O P G)$ showed the association with BMD-th in the osteoporotic and with BMD-fn in the nonosteoporotic post-menopausal women. In the nonosteoporotic post-menopausal women, the combined influence of $\mathrm{K} 3 \mathrm{~N}(O P G)$ and $\mathrm{Cdx} 2(V D R)$ on $\mathrm{BMD}$ was shown at all sites.

The analyzed genes were selected on the basis of the recently published data showing that $1 \alpha, 25(\mathrm{OH})_{2} \mathrm{D}_{3}$ suppresses OPG expression and enhances RANKL expression, indicating crosstalk of these two bone regulatory systems (Kondo et al. 2004). Therefore, seven SNPs were selected from the VDR, OPG and TNFSF11 genes. The SNPs from the VDR (BsmI, FokI and $\mathrm{Cdx} 2)$ and $O P G(\mathrm{~K} 3 \mathrm{~N})$ genes were selected, since they have often been associated with osteoporotic phenotype. For BsmI(VDR) and K3N(OPG), the association with $\mathrm{BMD}$ has also been shown in a smaller group of post-menopausal women from our population (Marc et al. 2000, Arko et al. 2005). In the TNFSF11 gene, SNPs $-290 \mathrm{C}>\mathrm{T},-643 \mathrm{C}>\mathrm{T}$ and $-693 \mathrm{G}>\mathrm{C}$ were selected on the basis of their previously proposed functional role in the regulation of the TNFSF11 expression (Mencej et al. 2008).
In the comparison of the osteoporotic and nonosteoporotic post-menopausal women, a significant difference in the genotype frequencies was observed for $F o k \mathrm{I}(V D R)$ and $\mathrm{Cdx} 2(V D R)$. However, these differences were not considered to be relevant since, in FokI $(V D R)$, no influence on BMD was found and, in $\mathrm{Cdx} 2(V D R)$, the genotypes GG and GA had different frequency distribution but comparable BMD values.

In post-menopausal osteoporosis, BsmI (VDR) and Cdx2(VDR), but not FokI $(V D R)$, were found to be associated with BMD-fn. The VDR gene is one of the most widely studied osteoporosis-related genes and numerous genetic association studies have yielded conflicting results (Thakkinstian et al. 2004, Fang et al. 2005, Zintzaras et al. 2006). For BsmI(VDR), the metaanalysis has shown contradictory results in BMD-fn (Cooper \& Umbach 1996, Gong et al. 1999, Thakkinstian et al. 2004). In the GENOMOS study, no association of BsmI-ApaI-TaqI(VDR) haplotype with any osteoporotic phenotype was found, whereas $\mathrm{Cdx} 2(V D R)$ was associated with risk of vertebral fracture (Uitterlinden et al. 2006). In FokI (VDR), no association with BMD has been found (Uitterlinden et al. 2006, Zintzaras et al. 2006).

In SNPs of the RANKL/RANK/OPG pathway genes, association between BMD-ls and $\mathrm{K} 3 \mathrm{~N}(O P G)$ and $-290 \mathrm{C}>\mathrm{T}($ TNFSF11) was established for post-menopausal osteoporosis in the present study. In $\mathrm{K} 3 \mathrm{~N}(O P G)$, women with GG genotype had significantly lower BMDls than those with GC or CC genotype, which is in accordance with several earlier studies (Langdahl et al. 2002, Arko et al. 2005, Choi et al. 2005, Zhao et al. 2005, 
Table 3 Bone mineral density in osteoporotic post-menopausal women in different genotype subgroups

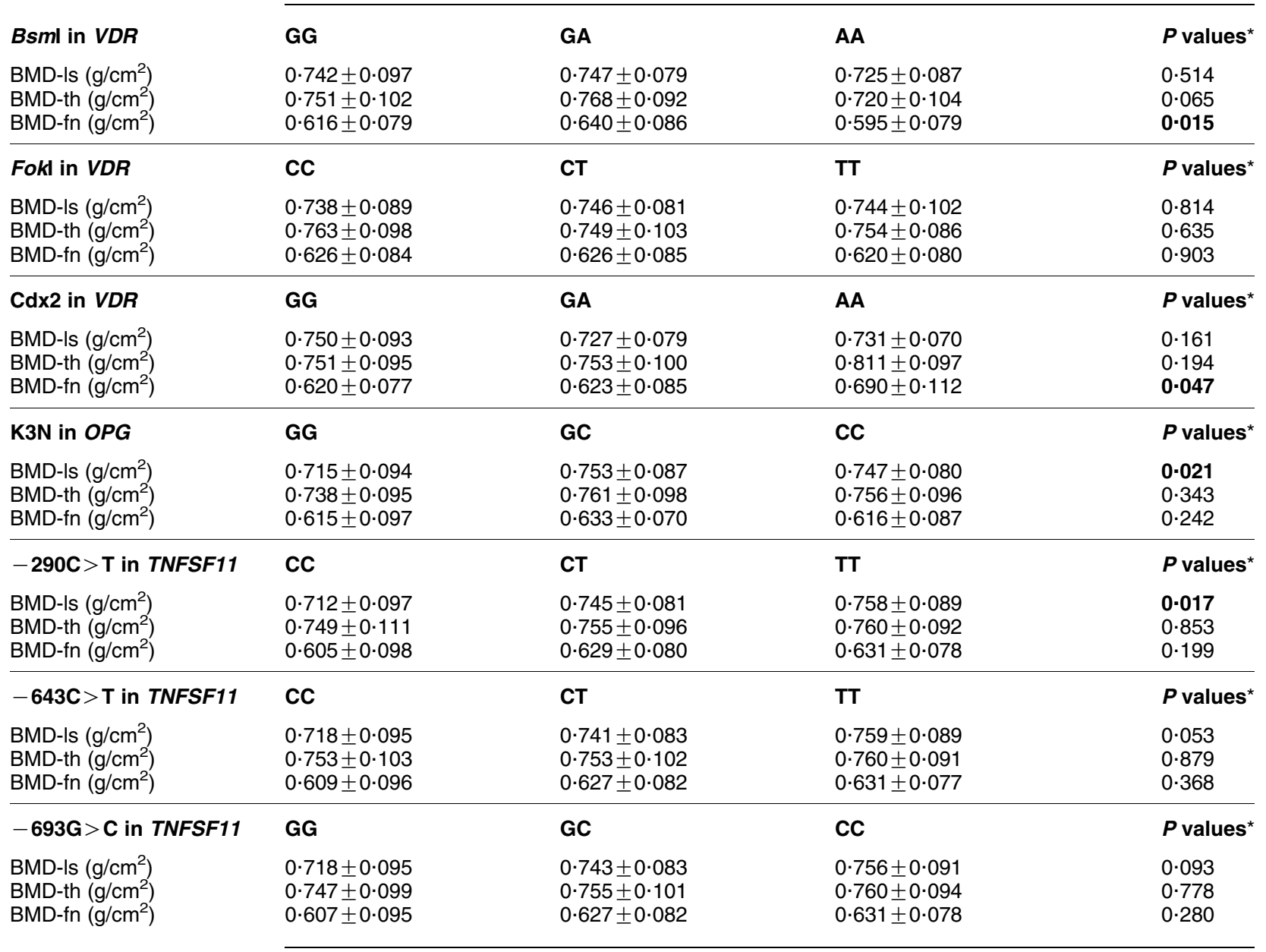

OPG, osteoprotegerin; TNFSF11, tumour necrosis factor superfamily, member 11; VDR, vitamin D receptor; BMD-ls, lumbar spine bone mineral density; BMD-th, total hip bone mineral density and BMD-fn, femoral neck bone mineral density. Values are means \pm s.D.s for bone mineral densities. ${ }^{*} P$ values were obtained in comparison of mean values with ANOVA testing. $P$ values $<0.05$ were considered statistically significant and are written in bold.

Kim et al. 2007, García-Unzueta et al. 2008). Our previous study on the TNFSF11 gene promoter SNPs, involving 404 post-menopausal women, showed association with BMD-ls for $-290 \mathrm{C}>\mathrm{T},-643 \mathrm{C}>\mathrm{T}$ and $-693 \mathrm{G}>\mathrm{C}$ (Mencej et al. 2008). In the present study, the association was only shown for $-290 \mathrm{C}>$ $\mathrm{T}($ TNFSF11), whereas in $-643 \mathrm{C}>\mathrm{T}($ TNFSF11) and $-693 \mathrm{G}>\mathrm{C}($ TNFSF11) the association was of borderline significance $(P=0.053$ and 0.093 respectively).

In the pre-menopausal women, only $\mathrm{Cdx} 2(V D R)$ was shown to be associated with BMD-fn and BMD-th. On the contrary, the GENOMOS study, involving pre- and post-menopausal women, revealed no association between the VDR gene SNPs and BMD in women (Uitterlinden et al. 2006). So far, the TNFSF11 gene promoter SNPs $-290 \mathrm{C}>\mathrm{T},-643 \mathrm{C}>\mathrm{T}$ and $-693 \mathrm{G}>\mathrm{C}$ have not been studied in pre-menopausal women, but the present results did not reveal their possible role in pre-menopausal BMD regulation. It seems that the VDR gene could play a role in the BMD regulation before menopause, but the data need to be further confirmed.

In elderly men, FokI $(V D R)$ was associated with BMD$\mathrm{fn}$ and BMD-ls. However, the GENOMOS study found no association of FokI (VDR) and BsmI(VDR) with osteoporotic phenotype in men, although Cdx2(VDR) was associated with the risk of vertebral fracture (Uitterlinden et al. 2006). Our results have also shown that $\mathrm{K} 3 \mathrm{~N}(O P G)$ has not been associated with osteoporotic phenotype in men. The TNFSF11 gene promoter SNPs $-290 \mathrm{C}>\mathrm{T},-643 \mathrm{C}>\mathrm{T}$ and $-693 \mathrm{G}>$ $\mathrm{C}$ have not been studied in elderly men and no association with BMD was shown in the present study. The data indicate the possible importance of the VDR gene, but not of the $O P G$ and TNFSF11 genes, in bone mass regulation in elderly men. 
Table 4 The analysis of interactions between polymorphisms in vitamin $\mathrm{D}$ receptor $(V D R)$, osteoprotegerin $(O P G)$ and tumour necrosis factor superfamily member 11 (TNFSF11) genes in osteoporotic and non-osteoporotic post-menopausal women

\section{Osteoporotic post-menopausal women}

$\begin{array}{lll}\text { K3N - Cdx2 } & & \\ \text { BMD-ls } & 0.723 & \mathbf{0 . 0 3 2} \\ \text { BMD-th } & 0.704 & \mathbf{0 . 0 4 9} \\ \text { BMD-fn } & 0.329 & \mathbf{0 . 0 2 2} \\ \text { K3N - Bsml } & & \\ \text { BMD-ls } & 0.143 & 0.335 \\ \text { BMD-th } & 0.525 & 0.291 \\ \text { BMD-fn } & 0.061 & 0.278 \\ \text {-290C>T-Cdx2 } & & \\ \text { BMD-ls } & 0.632 & 0.517 \\ \text { BMD-th } & 0.584 & 0.331 \\ \text { BMD-fn } & 0.926 & 0.263 \\ \text {-290C>T-Bsml } & & \\ \text { BMD-Is } & 0.457 & 0.645 \\ \text { BMD-th } & 0.439 & 0.447 \\ \text { BMD-fn } & 0.440 & 0.654 \\ \text {-290C>T-K3N } & & \\ \text { BMD-ls } & 0.177 & 0.477 \\ \text { BMD-th } & 0.041 & 0.097 \\ \text { BMD-fn } & 0.057 & 0.029\end{array}$

BMD-Is, lumbar spine bone mineral density; BMD-th, total hip bone minera density and BMD-fn, femoral neck bone mineral density. Numbers are $P$ values. $P$ values were obtained with two-way ANOVA testing. $P$ values $<0.05$ were considered statistically significant and are written in bold.

The main aim of our study was to investigate any interactions between different SNPs in the VDR, OPG and TNFSF11 genes. So far, the interaction had been studied only between $O P G$ and TNFSF11 gene polymorphisms. The $\mathrm{K} 3 \mathrm{~N}(O P G)$ polymorphism, alone and in combination with the rs2277438 polymorphism in the TNFSF11 gene, was identified to influence BMD-ls (Kim et al. 2007). Studying individual polymorphisms in the VDR, OPG and TNFSF11 genes, an association with $\mathrm{BMD}$ was found with $B s m \mathrm{I}(V D R)$ and $\mathrm{Cdx} 2(V D R)$, $\mathrm{K} 3 \mathrm{~N}(O P G)$ and $-290 \mathrm{C}>\mathrm{T}($ TNFSF11), but only in osteoporotic post-menopausal women. These significantly associated SNP were selected for further interaction analysis and the following combinations were prepared: $\mathrm{K} 3 \mathrm{~N}(O P G)-\mathrm{Cdx} 2(V D R), \mathrm{K} 3 \mathrm{~N}(O P G)$ $B s m \mathrm{I}(V D R),-290 \mathrm{C}>\mathrm{T}(T N F S F 11)-\mathrm{Cdx} 2(V D R),-290 \mathrm{C}>$ $\mathrm{T}($ TNFSF11)-Bsm $\mathrm{I}(V D R)$ and $-290 \mathrm{C}>\mathrm{T}($ TNFSF11)$\mathrm{K} 3 \mathrm{~N}(O P G)$. Since the pre-menopausal women and elderly men subgroups were rather small, the combined influence of different pairs of SNPs was only studied in the osteoporotic and non-osteoporotic post-menopausal women. Although no association of individual SNPs was observed in the non-osteoporotic women, the interactions were also studied in this subgroup. The combined influence can sometimes be observed even with the lack of individual effects. Comparison of the frequencies of combined genotypes between the osteoporotic and non-osteoporotic post-menopausal women revealed no significant differences. In the osteoporotic post-menopausal women, the combination of $-290 \mathrm{C}>\mathrm{T}($ TNFSF11) and $\mathrm{K} 3 \mathrm{~N}(O P G)$ was associated significantly with BMD-th $(P=0 \cdot 041)$. Interestingly, the individual effects of $-290 \mathrm{C}>\mathrm{T}($ TNFSF11) and $\mathrm{K} 3 \mathrm{~N}(O P G)$ on BMD-th were not significant, suggesting the importance of the interaction between the studied polymorphisms. Association of borderline significance with BMD-fn was observed for the K3N $(O P G)-B s m \mathrm{I}(V D R)$ and $-290 \mathrm{C}>\mathrm{T}($ TNFSF1 1$)-$ $\mathrm{K} 3 \mathrm{~N}(O P G)$ genetic combinations $(P=0.061$ and $0 \cdot 057)$. In the former, it seems that the $B s m \mathrm{I}(V D R)$ polymorphism is running the association, since the individual effect of the $B s m \mathrm{I}(V D R)$ on BMD-fn was also observed. In the latter, the CT and TT genotypes of the $-290 \mathrm{C}>\mathrm{T}($ TNFSF11) polymorphism seem to additionally increase BMD-fn in the $\mathrm{K} 3 \mathrm{~N}(O P G)$ genotypes.

In the non-osteoporotic post-menopausal women, the $\mathrm{K} 3 \mathrm{~N}(O P G)-\mathrm{Cdx} 2(V D R)$ combination was associated with BMD at all skeletal sites. The individual effects of $\mathrm{K} 3 \mathrm{~N}(O P G)$ and $\mathrm{Cdx} 2(V D R)$ were not significant at any skeletal site, suggesting the importance of the studied interaction. In non-osteoporotic women, the $\mathrm{C}$ allele of the $\mathrm{K} 3 \mathrm{~N}(O P G)$ was observed to markedly reduce BMDs in combination with the A allele of the $\mathrm{Cdx} 2(V D R)$. In the $-290 \mathrm{C}>\mathrm{T}(T N F S F 11)-\mathrm{K} 3 \mathrm{~N}(O P G)$ combination, the association was observed with BMD-fn and the association of borderline significance with BMD-th. As the individual effect of the $-290 \mathrm{C}>\mathrm{T}($ TNFSF11) was also observed, it seems that the $-290 \mathrm{C}>\mathrm{T}($ TNFSF11) is running the association.

Interestingly, different genes were shown to be associated with BMD in the studied subgroups. These findings suggest that various polymorphisms might influence BMD in different periods of life. The genetic influences differ between osteoporotic and non-osteoporotic post-menopausal women, suggesting that some polymorphisms might not cause osteoporosis, but when present can modify the degree of osteoporosis. These differences could have a great clinical impact, since even small changes in BMD may result in large changes of fracture risk. Diverse genetic influences were also observed in the pre- and post-menopausal women. The differences could be a result of numerous genetic interactions that were partly also addressed in our study. The association may also be modified by the influence of other osteoporosis-related polymorphisms and several environmental factors, such as dietary calcium and vitamin D intake, physical activity, etc.

Regarding the limitations of the study, firstly it must be remembered that BMD is only one of several parameters related to bone quality and risk of fracture. No data on fragility fractures and the quality of bone were available for the analysis. Secondly, the sample size 
is not optimal for the identification of genotypephenotype association. A relatively small sample size allowed only a limited power to detect individual effects and interactions. By expanding the sample size, we could further investigate genetic influence of the studied genes on the development of osteoporosis. Thirdly, the osteoporotic phenotype is usually affected by environmental factors. In our study, no data on dietary calcium and vitamin D intake, smoking habits, alcohol consumption and physical activity were collected and analysed. However, our group was ethnically homogenous and the participants originate from the same environment and have similar lifestyles. In our study, we did not fully cover all genetic variations in the VDR, OPG and TNFSF11 genes, since only the most common variants were studied. Additionally, biochemical markers of bone turnover were only measured in 152 post-menopausal women, thus not reflecting the intensity of bone turnover in premenopausal women and in men.

In conclusion, the results of our study support the involvement of gene-gene interactions between the VDR, OPG and TNFSF11 genes in the BMD regulation, particularly in osteoporotic and non-osteoporotic postmenopausal women. Under the combined influence of VDR, OPG and TNFSF11 genes, the association with BMD was markedly increased compared with the individual genetic effects of the genes under study. In osteoporotic women, a combination of $-290 \mathrm{C}>$ $\mathrm{T}($ TNFSF11) and $\mathrm{K} 3 \mathrm{~N}(O P G)$ was particularly important in the association with osteoporotic phenotype. In nonosteoporotic women, the interaction of $\mathrm{K} 3 \mathrm{~N}(O P G)$ and Cdx2(VDR) influences bone phenotype at all skeletal sites. To further investigate the genetic interactions between the VDR, OPG and TNFSF11 genes, the number of the studied SNPs should be increased and confirmed in the larger cohorts.

\section{Declaration of interest}

The authors declare that there is no conflict of interest that could be perceived as prejudicing the impartiality of the research reported.

\section{Funding}

This work was supported by grant P3-0298 provided by Ministry of Education, Science and Sport of the Republic of Slovenia.

\section{Acknowledgements}

We thank Prof. Roger Pain for advice on the English language.

\section{References}

Arko B, Prezelj J, Kocijancic A, Komel R \& Marc J 2005 Association of the osteoprotegerin gene polymorphisms with bone mineral density in postmenopausal women. Maturitas 51 270-279.
Baldock PA, Thomas GP, Hodge JM, Baker SUK, Dressel U, O'Loughlin PD, Nicholson GC, Briffa KH, Eisman JA \& Gardiner EM 2006 Vitamin D action and regulation of bone remodeling: suppression of osteoclastogenesis by the mature osteoblast. Journal of Bone and Mineral Research 21 1618-1626.

Choi JY, Shin A, Park SK, Chung HW, Cho SI, Shin CS, Kim H, Lee K, Lee KH, Kang C et al. 2005 Genetic polymorphisms of OPG, RANK, and ESR1 and bone mineral density in Korean postmenopausal women. Calcified Tissue International 77 152-159.

Cooper GS \& Umbach DM 1996 Are vitamin D receptor polymorphisms associated with bone mineral density? A meta-analysis Journal of Bone and Mineral Research 11 1841-1849.

Fang Y, van Meurs JB, d'Alesio A, Jhamai M, Zhao H, Rivadeneira F, Hofman A, van Leeuwen JPT, Jehan F, Pols HAP et al. 2005 Promoter and 3'-untranslated-region haplotypes in the vitamin D receptor gene predispose to osteoporotic fracture: the Rotterdam study. American Journal of Human Genetics 77 807-823.

García-Unzueta MT, Riancho JA, Zarrabeitia MT, Sañudo C, Berja A, Valero C, Pesquera C, Paule B, González-Macías J \& Amado JA 2008 Association of the $163 \mathrm{~A} / \mathrm{G}$ and $1181 \mathrm{G} / \mathrm{C}$ osteoprotegerin polymorphism with bone mineral density. Hormone and Metabolic Research 40 219-224.

Gong G, Stern H, Cheng S, Fong N, Mordeson J, Deng H \& Recker R 1999 The association of bone mineral density with vitamin D receptor polymorphisms. Osteoporosis International 9 55-64.

Hsu YH, Niu T, Terwedow HA, Xu X, Feng Y, Li Z, Brian JD, Rosen CJ, Laird N \& Xu X 2006 Variation in genes involved in the RANKL/RANK/OPG bone remodeling pathway are associated with bone mineral density at different skeletal sites in men. Human Genetics 118 568-577.

Kim S, Yamazaki M, Zella LA, Shevde NK \& Pike JW 2006 Activation of receptor activator of NF- $\mathrm{KB}$ ligand gene expression by 1,25 dihydroxyvitamin D3 is mediated through multiple long-range enhancers. Molecular and Cellular Biology 26 6469-6486.

Kim JG, Kim JH, Kim JY, Ku SY, Jee BC, Suh CS, Kim SH \& Choi YM 2007 Association between osteoprotegerin (OPG), receptor activator of nuclear factor kappaB (RANK), and RANK ligand (RANKL) gene polymorphisms and circulating OPG, soluble RANKL levels, and bone mineral density in Korean postmenopausal women. Menopause 14 913-918.

Kitazawa R, Kitazawa S \& Maeda S 1999 Promoter structure of mouse RANKL/TRANCE/OPGL/ODF gene. Biochimica et Biophysica Acta 1445 134-141.

Kondo T, Kitazawa R, Maeda S \& Kitazawa S $20041 \alpha, 25$ dihydroxyvitamin $\mathrm{D}_{3}$ rapidly regulates the mouse osteoprotegerin gene through dual pathways. Journal of Bone and Mineral Research 19 1411-1419.

Langdahl BL, Carstens M, Stenkjaer L \& Ericksen EF 2002 Polymorphisms in the osteoprotegerin gene are associated with osteoporotic fractures. Journal of Bone and Mineral Research 17 $1245-1255$.

Marc J, PrezeljJ, Komel R \& Kocijancic A 2000 Association of vitamin D receptor gene polymorphism with bone mineral density in Slovenian postmenopausal women. Gynecological Endocrinology 14 $60-64$.

Mencej S, Prezelj J, Kocijancic A, Ostanek B \& Marc J 2006 Association of TNFSF11 gene promoter polymorphisms with bone mineral density in postmenopausal women. Maturitas 55 219-236.

Mencej S, Albagha OME, Prezelj J, Kocjan T \& Marc J 2008 Tumour necrosis factor superfamily member 11 gene promoter polymorphisms modulate promoter activity and influence bone mineral density in postmenopausal women with osteoporosis. Journal of Molecular Endocrinology 40 273-279.

Morrison NA, Qi JC, Tokita A, Kelly PJ, Crofts L, Nguyen TV, Sambrook PN \& Eisman JA 1994 Prediction of bone density from vitamin D receptor alleles. Nature 367 284-287.

Mueller JC 2004 Linkage disequilibrium for different scales and applications. Briefings in Bioinformatics 5 355-364. 
Nerenz RD, Martowicz ML \& Pike JW 2008 An enhancer 20 kilobases upstream of the human receptor activator of NF-кB ligand gene mediates dominant activation by 1,25-dihydroxyvitamin D3. Molecular Endocrinology 22 1044-1056.

Ralston SH \& de Crombrugghe B 2006 Genetic regulation of bone mass and susceptibility to osteoporosis. Genes and Development $\mathbf{2 0}$ 2492-2506.

Richards JB, Rivadeneira F, Inouye M, Pastinen TM, Soranzo N, Wilson SG, Andrew T, Falchi M, Gwilliam R, Ahmadi KR et al. 2008 Bone mineral density, osteoporosis, and osteoporotic fractures: a genome-wide association study. Lancet 371 1505-1512.

Shepherd JA, Lu Y, Wilson K, Fuerst T, Genant H, Hangartner TN, Wilson C, Hans D, Leib ES \& International Society for Clinical Densitometry Committee on Standards of Bone Measurement 2006 Cross-calibration and minimum precision standards for dual-energy X-ray absorptiometry: the 2005 ISCD Official Positions. Journal of Clinical Densitometry 9 31-36.

Styrkarsdottir U, Halldorsson BV, Gretarsdottir S, Gudbjartsson DF, Walters GB, Ingvarsson T, Jonsdottir T, Saemundsdottir J, Center JR, Nguyen TV et al. 2008 Multiple genetic loci for bone mineral density and fractures. New England Journal of Medicine 358 2355-2365.

Thakkinstian A, d'Este C, Eisman J, Nguyen T \& Attia J 2004 Metaanalysis of molecular association studies: vitamin $\mathrm{D}$ receptor gene polymorphisms and BMD as a case study. Journal of Bone and Mineral Research 19 419-428.

Ueland T, Bollerslev J, Wilson SG, Dick IM, Islam FM, Mullin BH, Devine A \& Prince RL 2007 No association between OPG gene polymorphisms or serum levels and measures of osteoporosis in elderly Australian women. Bone 40 175-181.

Uitterlinden AG, Ralston SH, Brandi ML, Carey AH, Grinberg D, Langdahl BL, Lips P, Lorenc R, Obermayer-Pietsch B, Reeve J et al.
2006 The association between common vitamin D receptor gene variations and osteoporosis: a participant-level meta-analysis. Annals of Internal Medicine 145 255-264.

World Health Organisation 1994 Assessment of fracture risk and its application to screening for postmenopausal osteoporosis: report of a WHO Study Group. World Health Organization Technical Report Series 843 1-129.

Wynne F, Drummond F, O’Sullivan K, Daly M, Shanahan F, Molloy MG \& Quane KA 2002 Investigation of the genetic influence of the OPG, VDR (FokI), and COLIA1 Spl polymorphisms on BMD in the Irish population. Calcified Tissue International 71 $26-35$.

Yasuda H, Shima N, Nakagawa N, Yamaguchi K, Kinosaki M, Goto M, Mochizuki SI, Tsuda E, Morinaga T, Udagawa N et al. 1999 A novel molecular mechanism modulating osteoclast differentiation and function. Bone 25 109-113.

Zhao HY, Liu JM, Ning G, Zhao YJ, Zhang LZ, Sun LH, Xu MY, Uitterlinden AG \& Chen JL 2005 The influence of Lys3Asn polymorphism in the osteoprotegerin gene on bone mineral density in Chinese postmenopausal women. Osteoporosis International 16 1519-1524.

Zintzaras E, Rodopoulou P \& Koukoulis NG 2006 BsmI, TaqI, ApaI and FokI polymorphisms in the vitamin D receptor (VDR) gene and the risk of osteoporosis: a meta-analysis. Disease Markers 22 317-326.

Received in final form 20 November 2008

Accepted 8 January 2009

Made available online as an Accepted Preprint 8 January 2009 